\title{
Distinct roles of endogenous vascular endothelial factor receptor 1 and 2 in neural
}

protection after spinal cord injury

Munehisa Shinozaki ${ }^{\mathrm{a}}$, Masaya Nakamura ${ }^{\mathrm{b}}$, Tsunehiko Konomi ${ }^{\mathrm{b}}$, Yoshiomi Kobayashi ${ }^{\mathrm{b}}$,

Morito Takano $^{\mathrm{b}}$, Nobuhito Saito ${ }^{\mathrm{c}}$, Yoshiaki Toyama ${ }^{\mathrm{b}}$, Hideyuki Okano ${ }^{\mathrm{a}^{*}}$

${ }^{\text {a }}$ Department of Physiology, Keio University School of Medicine, 35 Shinanomachi,

Shinjuku-ku, Tokyo 160-8582, Japan

${ }^{\mathrm{b}}$ Department of Orthopedic Surgery, Keio University School of Medicine, 35 Shinanomachi,

Shinjuku-ku, Tokyo 160-8582, Japan

${ }^{\text {c }}$ Department of Neurosurgery, Graduate School of Medicine, University of Tokyo, 7-3-1

Hongo, Bunkyo-ku, Tokyo 113-8655, Japan

Corresponding author:

Masaya Nakamura

Department of Orthopedic Surgery, Keio University School of Medicine, 35 Shinanomachi,

Shinjuku-ku, Tokyo 160-8582, Japan

Tel: +81-3-5363-3812, Fax: +81-3-3353-6597 
E-mail: masa@a8.keio.jp

\section{Hideyuki Okano}

Department of Physiology, Keio University School of Medicine, 35 Shinanomachi,

Shinjuku-ku, Tokyo 160-8582, Japan

Tel: +81-3-5363-3747, Fax: +81-3-3357-5445

E-mail: hidokano@a2.keio.jp

Total number of pages: 37

Total number of figures: 6

Total number of tables: 0 


\section{Abstract}

Secondary degeneration after spinal cord injury (SCI) is caused by increased vascular permeability, infiltration of inflammatory cells, and subsequent focal edema. Therapeutic interventions using neurotrophic factors have focused on the prevention of such reactions to reduce cell death and promote tissue regeneration. Vascular endothelial growth factor (VEGF) is a potent angiogenic and vascular permeability factor. However, the effect of VEGF on SCI remains controversial. VEGF signaling is primarily regulated through two primary receptors, VEGF receptor 1 (VEGF-R1) and VEGF receptor 2 (VEGF-R2). The purpose of this study was to examine the effects of intraperitoneal administration of VEGF-R1- and VEGF-R2-neutralizing antibodies on a mouse model of SCI. VEGF-R1 blockade, but not VEGF-R2 blockade, decreased the permeability and infiltration of inflammatory cells, and VEGF-R2 blockade caused a significant increase in neuronal apoptosis in the acute phase of SCI. VEGF-R2 blockade decreased the residual tissue area and the number of neural fibers in the chronic phase of SCI. VEGF-R2 blockade worsened the functional recovery and prolonged the latency of motor evoked potentials. These data suggest that endogenous VEGF-R2 plays a crucial role in neuronal protection after SCI. 


\section{Keywords}

spinal cord injury, vascular endothelial growth factor, vascular endothelial growth factor receptor, neurotrophic factor, functional recovery

\section{Abbreviations}

VEGF, vascular endothelial growth factor

VEGF-R1, vascular endothelial growth factor receptor 1

VEGF-R2, vascular endothelial growth factor receptor 2

SCI, spinal cord injury

dextran-TMR, dextran tetramethylrhodamine

PI3-K, phosphatidylinositide 3-kinase

\section{INTRODUCTION}

Vascular endothelial growth factor (VEGF) is a protein that is associated with angiogenesis and potent vascular permeability. Its relation with the central nervous system has been mainly studied in models of ischemic stroke or brain tumor (Goldman et al., 1997; Abumiya et al., 1999; Proescholdt et al., 1999; van Bruggen et al., 1999; Zhang et al., 2000; Paul et al., 2001; 
Schoch et al., 2002). Recently, VEGF has also been attracting attention as a neuroprotective and neurotrophic factor involved in neurovascular wiring or vascular niche (Arai et al., 2009).

Several reports have reported the functional recovery from spinal cord injury (SCI) after administration of VEGF (Facchiano et al., 2002; Widenfalk et al., 2003). However, other reports found that hyper-vascular permeability aggravated tissue edema when VEGF was administered in the acute phase of SCI (van Bruggen et al., 1999; Paul et al., 2001; Schoch et al., 2002). Therefore, the effect of VEGF on recovery after SCI remains controversial. One reason for the conflicting results is a lack of consideration for the different subtypes of VEGFs and VEGF receptors. There are six subtypes of VEGF (VEGF-A to VEGF-F) and at least four subtypes of VEGF receptors: R1 (VEGF-R1), R2 (VEGF-R2), R3, and neuropilin-1. Thus, combinations of VEGF and VEGF receptor subtypes are complex and vary with species (Takahashi \& Shibuya, 2005; Olsson et al., 2006). In cancer therapy, a VEGF-A antagonist is clinically used to inhibit new blood vessels and control cancers, and new drugs that act on different receptors have been investigated to enhance the therapeutic effect and reduce adverse effects (Chung et al., 2006).

VEGF signaling is regulated mainly through VEGF-R1 and VEGF-R2, and expression of these genes after ischemic stroke, brain trauma, and SCI has been investigated to identify potential VEGF interventions (Lennmyr et al., 1998; Marti et al., 2000; Sun et al., 2003; 
Manoonkitiwongsa et al., 2004; Winkler et al., 2004; Skold et al., 2005; Choi et al., 2007;

Kumai et al., 2007; Lee et al., 2009). In the present study, we administered VEGF-R1 or

VEGF-R2 neutralizing antibodies after SCI in adult mice, and evaluated vascular permeability, angiogenesis, neuroprotection, and functional recovery to determine the endogenous role of these receptors in vivo.

\section{METHODS}

\section{Spinal cord injury and antibody administration}

Thirty-nine 6-week-old adult female C57BL/6J mice (body weight, 16-20 g) were used in this study. Animals were anesthetized by intraperitoneal injection of ketamine and xylazine, and the dorsal surface of the dura mater at the T10 level was exposed by laminectomy. Moderate contusion SCI was induced in each mouse using an Infinite Horizen impactor (Precision Systems, Kentucky, IL, USA; impact force, 70 kdyn), as reported previously (Tsuji et al., 2010). The muscles and skin were closed in layers. Immediately after the injury, polyclonal goat anti-VEGF-R1 antibody (50 $\mu \mathrm{g}, \mathrm{R} \& \mathrm{D}$ systems, Minneapolis, MN, USA) was intraperitoneously administered to 14 animals (VEGF-R1-neutralized group), polyclonal goat anti-VEGF-R2 antibody (50 $\mu \mathrm{g}, \mathrm{R} \& \mathrm{D}$ systems) was intraperitoneously administered to 12 animals (VEGF-R2-neutralized group), and goat normal IgG (50 $\mu \mathrm{g}, \mathrm{R} \& \mathrm{D}$ systems) was 
intraperitoneously administered to 17 animals (control group). Those antibodies (Usui et al., 2004; Kim et al., 2010; Schreurs et al., 2012) and doses (Silvestre et al., 2003; Ohki et al., 2005; Pitchford et al., 2012) were determined according to previous reports. All animals were then placed in a temperature-controlled chamber until thermoregulation was re-established. Manual voiding of the bladder was performed twice daily until reflex bladder emptying was re-established. All experiments and procedures were approved by the Keio University Animal Research Committee (No. 086029) and performed in accordance with the Laboratory Animal Welfare Act, the Guide for the Care and Use of Laboratory Animals (National Institutes of Health, Bethesda, MD, USA), and the Guidelines and Policies for Animal Surgery provided by the Animal Study Committees of the Central Institute for Experimental Animals and of Keio University.

\section{Histological analyses}

Mice were deeply anesthetized and transcardially perfused with $4 \%$ paraformaldehyde in the acute phase of SCI ( $8 \mathrm{~h}$ after contusion, $\mathrm{n}=12$ ) or the chronic phase of SCI (56 d after contusion, $n=27$ ). Dissected spinal cords were post-fixed overnight in $4 \%$ paraformaldehyde, and soaked overnight in $10 \%$ sucrose then soaked for another period of time in $30 \%$ sucrose, and embedded in OCT compound (Sakura Finetechnical, Tokyo, Japan), and sectioned in the 
sagittal or axial plane at $20 \mu \mathrm{m}$ on a cryostat (CM3050 S; Leica, Nussloch GmbH, Germany).

Histological examinations in the acute phase of SCI

To evaluate neural apoptosis in the acute phase of SCI, tissue sections from the spinal cords dissected 8 h after SCI (n=4 VEGF-R1-neutralized mice, n=4 VEGF-R2-neutralized mice and $n=4$ control mice) were stained with anti-neuronal nuclei (NeuN, mouse IgG, 1:1,000; Sigma, St. Louis, MO, USA) anti-cleaved caspase-3 (rabbit IgG, 1:100; Cell Signaling, Beverly, MA, USA) and anti-Cd11b (rat IgG, 1:200; Serotec, Oxford, UK)). Histological examinations in the chronic phase of SCI To evaluate the sparing of neural tissue in the chronic phase of SCI, the spinal cords were dissected $56 \mathrm{~d}$ after SCI ( $\mathrm{n}=10$ VEGF-R1-neutralized mice, n=8 VE GF-R2-neutralized mice and $n=9$ control mice) were stained with hematoxylin-eosin (HE), eriochrome cyanine (EC), and Nissl. To evaluate the endothelial cells in the chronic phase of SCI, tissue sections were stained with anti-5-hydroxytrypamine (5-HT, goat IgG, 1:200; Immunostar, Hudson, WI, USA) and antiplatelet endothelial cell adhesion molecule-1 (PECAM-1, rat IgG, 1:50; BD Bioscience Pharmingen, San Diego, CA, USA).

Vascular permeability assay

SCI collapses the blood-brain barrier at the lesion epicenter and increases vascular permeability. Vascular permeability in the acute phase of SCI was determined by measuring 
the infiltration of dextran tetramethylrhodamine (dextran-TMR, $70000 \mathrm{MW}$, Molecular probes, Eugene, OR, USA) from blood vessels into the spinal cord, as reported previously (Armulik et al., 2010). Eight hours after SCI, dextran-TMR (2.5\%, $2 \mathrm{mg})$ was infused through the tail vein of anaesthetized mice ( $n=4$ VEGF-R1-neutralized mice, $n=4$ VEGF-R2-neutralized mice and $n=4$ control mice). After 60 min, animals were perfused and the spinal cords were immediately dissected. Dissected spinal cords were post-fixed overnight in $4 \%$ paraformaldehyde, soaked overnight in 10\% followed by 30\% sucrose, embedded in OCT compound, and sectioned in the axial plane at $20 \mu \mathrm{m}$ on a cryostat.

\section{Quantitative analyses of tissue sections}

To quantify the cells of interest, images of the stained sections were obtained by fluorescence microscopy (BZ-9000; Keyence, Osaka, Japan), manually outlined them, and the number of cells was quantified using Dynamic cell count BZ-HIC software. Threshold values were maintained at a constant level for all analyses using BZ-HIC. The HE- and EC- positive area was quantified in the axial sections captured at x100 magnification: the lesion epicenter, and 1, 2, 3, and 4 mm rostral and caudal to the epicenter. The Nissl- ,dextran-TMR-, and CD11b-positive area and the number of NeuN- and cleaved caspase-3-positive cells were quantified in the axial sections captured at x100 magnification: the lesion epicenter, and $4 \mathrm{~mm}$ 
rostral and caudal to the epicenter. The number of PECAM-1-postive cells and the

5-HT-positive area were quantified in nine regions of the midsagittal sections that had been scanned and tiled transversely at the lesion epicenter and captured at x400 magnification: 1, 2, 3 , and $4 \mathrm{~mm}$ rostral and caudal to the epicenter.

\section{Behavioral analyses}

Locomotor performance was evaluated once a week for 8 weeks after SCI using the Basso mouse scale (BMS) (Basso et al., 2006), in which a score of zero indicates complete paralysis of the hind limbs and a score of nine denotes full mobility. Animals were allowed to move freely for 5 min while two examiners observed the hindlimb movements, and the average score from the two examiners was used.

\section{Electrophysiology}

Motor evoked potentials (MEP) were used to evaluate the neuronal circuit from the upper cervical cord to the hindlimbs $56 \mathrm{~d}$ after SCI in nine mice in the VEGF-R1-neutralized group, eight mice in the VEGF-R2-neutralized group, and nine mice in the control group. MEPs were evoked and recorded by electromyography and an evoked potential response unit (Neuropack, MEB-9402, Nihon Kohden, Tokyo, Japan). Mice were given an intraperitoneal 
injection of ketamine $(100 \mathrm{mg} / \mathrm{kg})$ and xylazine $(10 \mathrm{mg} / \mathrm{kg})$, and 10 square-wave stimuli of $0.2 \mathrm{~ms}$ duration with a stimulus intensity of up to $0.6 \mathrm{~mA}$ were delivered through the occipitocervical area of the spinal cord (Nori et al., 2011; Yasuda et al., 2011). The active electrode was placed in the muscle belly, and the reference electrode was placed near the distal tendon. The ground electrode was placed on the tail. MEP onset latency was measured as the length of time between the stimulus and the onset of the first increase in the amplitude of the el ectromyography response.

\section{Statistical analyses}

One-way ANOVA followed by the Tukey-Kramer test for multiple comparisons was used to compare histological outcomes and MEP latency across the three groups. Repeated-measures two-way ANOVA, followed by the Tukey-Kramer post-hoc test, was used to compare BMS scores across the nine time points (week 0 to week 8 after SCI) and the three groups. The strength of correlation was determined using Pearson's correlation coefficient. 


\section{RESULTS}

\section{Histological examinations in the acute phase of SCI}

Figure $1 \mathrm{~A}$ and $1 \mathrm{~B}$ are representative images of the lesion epicenter obtained $8 \mathrm{~h}$ after contusion in the control group, immunostained with anti-NeuN antibodies and anti-cleaved caspase- 3 antibodies, respectively. Figure $1 \mathrm{C}$ is the merged image of $1 \mathrm{~A}$ and $1 \mathrm{~B}$.

NeuN-positive neurons did not show remarkable reduction from the rostral to caudal sections of the spinal cord, and there was no decrease in the number of NeuN-positive neurons in the lesion epicenter (Figure 1D). By contrast, although only a small number of NeuN- and cleaved caspase 3-positive apoptotic neural cells were present in the rostral and caudal sections of the spinal cord, a large number of apoptotic neural cells were present in the lesion epicenter (Figure 1E). The number of neural cells was similar in VEGF-R1-neutralized, VEGF-R2-neutralized, and control groups (Figure 1D), but there were significantly more apoptic neural cells in the VEGF-R2-neutralized group than in the control group (Figure 1E).

Although both the rostral and caudal sections showed a slight increase in the total dextran-TMR-positive area, indicating a small el evation in vascular permeability,, the epicenter sections showed large dextran-TMR-positive areas in the spinal cord tissue, especially at the dorsal side (Figure 2A-C), which reflected the collapse of the blood-brain barrier. Quantitative analysis of these areas revealed that VEGF-R1 neutralization suppressed 
hyperpermeability after SCI (Figure 2G). Although infiltration of CD11b-positive

inflammatory cells also increased in the epicenter sections in all the groups (Figure 2D-F),

the VEGF-R1-neutralized group had significantly fewer CD11b-positive cells (Figure 2H).

\section{Histological examinations in the chronic phase of SCI}

The VEGF-R2-neutralized group had a significant reduction of the HE-positive spared spinal cord areas in accordance with the significant decreases in the Nissl-positive neural cell areas and the EC-positive neural fiber areas at the epicenter compared to the control group , while the VEGF-R1-neutralized group showed no significant reduction compared to the control group (Figure 3).

For the functional recovery of SCI, angiogenesis and the presence of 5-HT positive fibers of raphe spinal tracts are likely to play crucial roles (Tsuji et al., 2010; Nori et al., 2011). Thus, we investigated PECAM-1 positive endothelial cells and 5-HT fibers in the lesion sites. Figure 4A and 4B are representative images of the spinal cords of the control group $56 \mathrm{~d}$ after contusion immunostained with anti-PECAM-1 antibodies and anti-5-HT antibodies (B), respectively. Figure $4 \mathrm{C}$ is the merged image of $4 \mathrm{~A}$ and $4 \mathrm{~B}$. There were fewer PECAM-1-positive cells and 5-HT-positive fibers at the lesion epicenter than at rostral and caudal sections of the spinal cord (Figure 4D, E), but the number of PECAM-1-positive cells 
and 5-HT-positive fibers was similar across the three groups, suggesting that the single injection of the neutralizing antibody for the VEGF receptors did not affect long-term angiogenesis. Double-stained sections revealed that some 5-HT-positive neurons were dependent from PECAM-1-positive cells, whereas there was a significant correlation between the distribution of 5-HT-positive fibers and PECAM-1-positive cells ( $r$ = 0.47; Figure 4F).

\section{Behavioral and electrophysiological analyses}

The BMS score was zero immediately after SCI and gradually recovered to a plateau in the 3 weeks following SCI (Figure 5A). VEGF-R1-neutralized and control mice achieved weight-bearing stepping. VEGF-R2-neutralized mice showed a significantly lower BMS score, and half of the VEGF-R2-neutralized mice did not achieve weight-bearing stepping.

The average MEP latency was $4.47 \pm 0.16 \mathrm{~ms}$ in the VEGF-R1-neutralized group, $4.75 \pm$ $0.14 \mathrm{~ms}$ in the VEGF-R2-neutralized group, and $4.16 \pm 0.09 \mathrm{~ms}$ in the control group (Figure 5B). This latency was significantly longer in the VEGF-R2-neutralized group than the control group. 


\section{DISCUSSION}

In this study we demonstrated the effect of subtype-specific blockade of VEGF receptors on SCI by administrating neutralizing antibodies of two VEGF receptors to a mouse model of SCI. Blockade of VEGF-R2 accelerated acute neural apoptosis and decreased neural tissue in the chronic phase. Blockade of VEGF-R1 protected the blood-brain barrier in the acute phase, but did not lead to any long-term beneficial effects in histological outcomes or functional behavior. Understanding the differential role of endogenous VEGF receptors in acute and chronic phases of SCI is a preliminary step toward effective use of VEGF for the treatment of SCI.

\section{Differential roles of endogenous VEGF-R1 and VEGF-R2 after SCI}

VEGF signals are considered as neurotrophic factors (Sondell et al., 1999; Jin et al., 2000;

Oosthuyse et al., 2001; Jin et al., 2002; Sun et al., 2003). Recent studies have demonstrated the direct neurotrophic effects of VEGF on peripheral nerves (Sondell et al., 1999; Sondell et al., 2000), and reported increased density and survival of neurons in VEGF-treated mesencephalic explant cultures (Silverman et al., 1999). Successful neurotrophic or neuroprotective and tissue-sparing effects have also been reported after VEGF treatment in traumatic SCI (Facchiano et al., 2002; Widenfalk et al., 2003). VEGF-R1 and VEGF-R2 are 
both from the VEGF family of receptors and have common ligands, but they are up-regulated differently after SCI (Choi et al., 2007). In the present data, VEGF-R1-neutralized mice were similar to control mice with respect to acute neural apoptosis, chronic histology, and the results of chronic behavioral assessment, but the VEGF-R1-neutralized mice had significantly lower acute vascular permeability and significantly less acute infiltration of inflammatory cells. VEGF-R2-neutralized mice had significantly more acute neural apoptosis, significantly less chronic residual tissue, neural cells, and myelinated fibers, and a significantly worse functional recovery than control mice. These data suggest that to maximize the neuroprotective and neurotrophic effects of VEGF for SCI therapy, a subtype-specific target configuration is required.

\section{VEGF-R2 as a neuroprotective receptor}

Inhibition of VEGF-R2 promoted neural apoptosis, indicating that VEGF-R2 acts as a neuroprotective factor in the acute phase of SCI. Administration of VEGF-R2 neutralizing antibody increased the number of apoptotic neural cells in the acute phase of SCI, and these neurons did not recover in the chronic phase. This supports reports that inhibition of VEGF-R2 induced apoptosis of spinal anterior horn cells under hypoxia (Shiote et al., 2005). In addition, it has been reported that VEGF exerts a direct neuroprotective effect on cultured 
neurons exposed to hypoxia via VEGF-R2 in the central nervous system (Jin et al., 2000).

VEGF can stimulate neurogenesis via VEGF-R2 in vitro (in cultured cortical neurons) and in vivo (in adult rats) (Jin et al., 2002). In the ischemic brain, there is increased survival of neurons after VEGF treatment, and this is primarily mediated via VEGF-R2 both in vitro (Oosthuyse et al., 2001; Ogunshola et al., 2002; Rosenstein et al., 2003; Khaibullina et al., 2004; Skold et al., 2004) and in vivo (Sun et al., 2003; Manoonkitiwongsa et al., 2004). Together, these data suggest that VEGF-R2 acts as a neuroprotective receptor in central nervous diseases, including SCI.

Recent in vitro and in vivo studies have demonstrated that VEGF can activate several intracellular signal transduction systems, including the phosphatidylinositide 3-kinase/Akt (PI3-K/Akt) and MEK/ERK pathways (Jin et al., 2000; Jin et al., 2002; Kilic et al., 2006). Matsuzaki et al. reported that inhibition of VEGF-R2 expression in hippocampal neuronal culture completely blocks the neuroprotective effect of VEGF against glutamate toxicity(Matsuzaki et al., 2001). They also observed that the binding of VEGF to VEGF-R2 activated Akt and ERK, and suggested that the protective effect of VEGF was mediated by VEGF-R2 through two independent pathways, namely, the PI3-K/Akt and the MEK/ERK pathways. VEGF is important not only for endothelial cell proliferation, but also for endothelial survival, and these effects are also mediated via VEGF-R2 (Yang \& de Bono, 
1997; Rosenstein et al., 1998; Gerber et al., 1999; Darland et al., 2003; Huang et al., 2003). Previous studies showing beneficial effects of VEGF in the ischemic brain (Hayashi et al., 1998) and injured spinal cord (Facchiano et al., 2002; Widenfalk et al., 2003) have pointed out the importance of the protection and survival of endothelial cells. Hypothetically, enhanced survival of endothelial cells could reduce capillary breakdown and bleeding, and preserve adequate microcirculation and perfusion, thereby contributing to increased neuronal survival (Oosthuyse et al., 2001).

\section{VEGF-R1 affects vascular permeability, but not long-term condition}

Previous studies have demonstrated the involvement of VEGF in angiogenesis and breakdown of the blood-brain barrier after ischemic injuries, inflammation, and brain tumors (Goldman et al., 1997; Abumiya et al., 1999; Proescholdt et al., 1999; van Bruggen et al., 1999; Zhang et al., 2000; Paul et al., 2001; Schoch et al., 2002; Croll et al., 2004), and there are indications of a temporal and spatial correlation between blood-brain barrier leakage and VEGF expression (Zhang et al., 2002). Different treatment strategies have been explored that show reduction of edema and infarction volume after blockage of VEGF in the ischemic brain (van Bruggen et al., 1999; Paul et al., 2001; Schoch et al., 2002). Although VEGF-R1 has been shown to regulate the amount of VEGF that binds VEGF-R2 via its action as a VEGF decoy 
receptor, there is also circumstantial evidence that VEGF-R1 can be phosphorylated by VEGF, and that this directly stimulates growth and migration of non-endothelial cells (Meyer \& Rahimi, 2003). Recent studies reported that the reduction in brain edema after VEGF-R1 inhibition was associated with attenuation of blood-brain barrier permeability and macrophage/monocyte infiltration (Kumai et al., 2007), and that hypoxia-induced hyperpermeability was mediated by activation of VEGF-R1 (Vogel et al., 2007). It has also been reported that VEGF-R2 inhibition has no effect on vascular permeability in the ischemic brain (Shimotake et al., 2010). In agreement with these studies, we demonstrated that VEGF-R1 neutralization inhibited hyper-vascular permeability and infiltration of inflammatory cells after SCI.

Recent studies suggest the mechanism underlying the reduction of permeability and inflammatory cell infiltration. VEGF-R1 expressed on the surface of monocytes/macrophages is involved in ligand-dependent cell migration (Sawano et al., 2001), and VEGF-R1 is a positive regulator of monocyte and macrophage migration (Takahashi \& Shibuya, 2005; Olsson et al., 2006). In an in vitro study, Forstreuter et al. found that microglial cells expressed VEGF-R1 mRNA and protein, and that VEGF induced chemotaxis and the proliferation of microglial cells (Forstreuter et al., 2002). These data suggest that VEGF enables inflammatory cells to enter the spinal cord via VEGF-R1. It has been suggested that 
the change in permeability can be mediated by VEGF-R1-, but not VEGF-R2-, induction of the PI3-K/Akt pathway (Vogel et al., 2007), suggesting that inhibition of the PI3-K/Akt pathway reduces brain edema in hypoxia/VEGF-induced downstream signaling events observed in vitro and in vivo.

Tissue edema is one of the main causes of secondary damage after SCI (Shingu et al., 1989; Blight, 1991; Popovich et al., 1996; Tator \& Koyanagi, 1997; Mautes et al., 2000; Bilgen et al., 2001; Westergren et al., 2001; Casella et al., 2002; Loy et al., 2002; Narayana et al., 2004; Maikos \& Shreiber, 2007). Although application of VEGF after SCI increases vascular permeability and tissue edema in the spinal cord, deterioration of functional recovery has not been reported (Patel et al., 2009; Sundberg et al., 2010). In the present study, although VEGF-R1 blockade decreased the infiltration of inflammatory cells and hyper-permeability, spared tissue and functional recovery were similar in VEGF-R1-neutralized mice and control mice. Together, these data suggest that the VEGF-R1-mediated change in vascular permeability and infiltration of inflammatory cells has little influence on secondary damage after SCI. 


\section{CONCLUSION}

Endogenous VEGF-R1 and VEGF-R2 played distinct roles after SCI. VEGF-R1 influenced vascular permeability and the infiltration of inflammatory cells, whereas VEGF-R2 acted as a neuroprotective receptor. A differential configuration for each receptor may be required for the effective use of VEGF as a treatment for SCI (Figure 6). 


\section{ACKNOWLEDGEMENTS}

This study was supported by grants obtained from Research Center Network for Realization of Regenerative Medicine, Centers for Clinical Application Research on Specific

Disease/Organ, and the Ministry of Education, Culture, Sports, Science and Technology (MEXT) Japan to Hideyuki Okano; from CREST and JST to Masaya Nakamura; from the “Funding Program for World-leading Innovative R\&D on Science and Technology” to Hideyuki Okano. 


\section{References}

Abumiya, T., Lucero, J ., Heo, J .H., Tagaya, M., K oziol, J .A., Copeland, B.R. \& del Zoppo, G.J . (1999) Activated microvessels express vascular endothelial growth factor and integrin al pha(v)beta3 during focal cerebral ischemia. J Cereb Blood Flow Metab, 19, 1038-1050.

Arai, K., J in, G., Navaratna, D. \& Lo, E.H. (2009) Brain angiogenesis in developmental and pathological processes: neurovascular injury and angiogenic recovery after stroke. FEBS J, 276, 4644-4652.

Armulik, A., Genove, G., Mae, M., Nisancioglu, M.H., Wallgard, E., Niaudet, C., He, L., N orlin, J ., Lindblom, P., Strittmatter, K., J ohansson, B.R. \& Betsholtz, C. (2010) Pericytes regulate the blood-brain barrier. Nature, 468, 557-561.

Bilgen, M., Abbe, R. \& Narayana, P.A. (2001) Dynamic contrast-enhanced MRI of experimental spinal cord injury: in vivo serial studies. Magn Reson Med, 45, 614-622.

Blight, A.R. (1991) Morphometric analysis of a model of spinal cord injury in guinea pigs, with behavioral evidence of delayed secondary pathology. J Neurol Sci, 103, 156-171.

Casella, G.T., Marcillo, A., Bunge, M.B. \& Wood, P.M. (2002) New vascular tissue rapidly replaces neural parenchyma and vessels destroyed by a contusion injury to the rat spinal cord. Exp Neurol, 173, 63-76.

Choi, J .S., Kim, H.Y., Cha, J .H., Choi, J .Y., Park, S.I ., J eong, C.H., J eun, S.S. \& Lee, M.Y. (2007) U pregulation of vascular endothelial growth factor receptors FIt-1 and FIk-1 following acute spinal cord contusion in rats. J Histochem Cytochem, 55, 821-830.

Chung, G.G., Yoon, H.H., Zerkowski, M.P., Ghosh, S., Thomas, L., Harigopal, M., Charette, L.A., Salem, R.R., Camp, R.L., Rimm, D.L. \& Burtness, B.A. (2006) Vascular endothelial growth factor, FLT-1, and FLK-1 analysis in a pancreatic cancer tissue microarray. Cancer, 106, 1677-1684.

Croll, S.D., Goodman, J .H. \& Scharfman, H.E. (2004) Vascular endothelial growth factor (VEGF) in seizures: a double-edged sword. Adv Exp Med Biol, 548, 57-68.

Darland, D.C., Massingham, L.J ., Smith, S.R., Piek, E., Saint-Geniez, M. \& D'Amore, P.A. (2003) 
Pericyte production of cell-associated VEGF is differentiation-dependent and is associated with endothelial survival. Dev Biol, 264, 275-288.

Facchiano, F., Fernandez, E., Mancarella, S., Maira, G., Miscusi, M., D'Arcangelo, D., Cimino-Reale, G., Falchetti, M.L., Capogrossi, M.C. \& Pallini, R. (2002) Promotion of regeneration of corticospinal tract axons in rats with recombinant vascular endothelial growth factor al one and combined with adenovirus coding for this factor. J Neurosurg, 97, 161-168.

Forstreuter, F., Lucius, R. \& Mentlein, R. (2002) Vascular endothelial growth factor induces chemotaxis and proliferation of microglial cells. J Neuroimmunol, 132, 93-98.

Gerber, H.P., Hillan, K.J ., Ryan, A.M., Kowalski, J ., Keller, G.A., Rangell, L., Wright, B.D., Radtke, F., Aguet, M. \& Ferrara, N. (1999) VEGF is required for growth and survival in neonatal mice. Development, 126, 1149-1159.

Goldman, C.K., Bharara, S., Palmer, C.A., Vitek, J ., Tsai, J .C., Weiss, H.L. \& Gillespie, G.Y. (1997) Brain edema in meningiomas is associated with increased vascular endothelial growth factor expression. Neurosurgery, 40, 1269-1277.

Hayashi, T., Abe, K. \& I toyama, Y. (1998) Reduction of ischemic damage by application of vascular endothelial growth factor in rat brain after transient ischemia. J Cereb Blood Flow Metab, 18, 887-895.

Huang, J ., Frischer, J .S., Serur, A., Kadenhe, A., Yokoi, A., McCrudden, K.W., New, T., O'Toole, K., Zabski, S., Rudge, J .S., Holash, J ., Yancopoulos, G.D., Yamashiro, D.J . \& Kandel, J J . (2003) Regression of established tumors and metastases by potent vascular endothelial growth factor blockade. Proc Natl Acad Sci U SA, 100, 7785-7790.

J in, K., Zhu, Y., Sun, Y., Mao, X.O., Xie, L. \& Greenberg, D.A. (2002) Vascular endothelial growth factor (VEGF) stimulates neurogenesis in vitro and in vivo. Proc Nat/ Acad Sci U SA, 99, 11946-11950.

J in, K.L., Mao, X.O. \& Greenberg, D.A. (2000) Vascular endothelial growth factor: direct neuroprotective effect in in vitro ischemia. Proc Natl Acad Sci U S A, 97, 10242-10247.

Khaibullina, A.A., Rosenstein, J .M. \& Krum, J .M. (2004) Vascular endothelial growth factor 
promotes neurite maturation in primary CNS neuronal cultures. Brain Res Dev Brain Res, 148, 59-68.

Kilic, U., Kilic, E., J arve, A., Guo, Z., Spudich, A., Bieber, K., Barzena, U., Bassetti, C.L., Marti, H.H. \& Hermann, D.M. (2006) Human vascular endothelial growth factor protects axotomized retinal ganglion cells in vivo by activating ERK-1/2 and Akt pathways. J Neurosci, 26, 12439-12446.

Kim, Y.S., Choi, S.J ., Tae, Y.M., Lee, B.J ., J eon, S.G., Oh, S.Y., Gho, Y.S., Zhu, Z. \& Kim, Y.K. (2010) Distinct roles of vascular endothelial growth factor receptor-1- and receptor-2-mediated signaling in T cell priming and Th17 polarization to lipopolysaccharide-containing allergens in the lung. J Immunol, 185, 5648-5655.

Kumai, Y., Ooboshi, H., I bayashi, S., I shikawa, E., Sugimori, H., Kamouchi, M., Kitazono, T., Egashira, K. \& Iida, M. (2007) Postischemic gene transfer of soluble FIt-1 protects against brain ischemia with marked attenuation of blood-brain barrier permeability. J Cereb Blood Flow Metab, 27, 1152-1160.

Lee, J .S., J ang, D.J ., Lee, N., Ko, H.G., Kim, H., Kim, Y.S., Kim, B., Son, J ., Kim, S.H., Chung, H., Lee, M.Y., Kim, W.R., Sun, W., Zhuo, M., Abel, T., Kaang, B.K. \& Son, H. (2009) Induction of neuronal vascular endothelial growth factor expression by CAMP in the dentate gyrus of the hippocampus is required for antidepressant-like behaviors. J Neurosci, 29, 8493-8505.

Lennmyr, F., Ata, K.A., Funa, K., Olsson, Y. \& Terent, A. (1998) Expression of vascular endothelial growth factor (VEGF) and its receptors (FIt-1 and FIk-1) following permanent and transient occlusion of the middle cerebral artery in the rat. J Neuropathol Exp Neurol, 57, 874-882.

Loy, D.N., Crawford, C.H., Darnall, J .B., Burke, D.A., Onifer, S.M. \& Whittemore, S.R. (2002) Temporal progression of angiogenesis and basal lamina deposition after contusive spinal cord injury in the adult rat. J Comp Neurol, 445, 308-324.

Maikos, J .T. \& Shreiber, D.I . (2007) I mmediate damage to the blood-spinal cord barrier due to mechanical trauma. J Neurotrauma, 24, 492-507.

Manoonkitiwongsa, P.S., Schultz, R.L., McCreery, D.B., Whitter, E.F. \& Lyden, P.D. (2004) Neuroprotection of ischemic brain by vascular endothelial growth factor is critically 
dependent on proper dosage and may be compromised by angiogenesis. J Cereb Blood Flow Metab, 24, 693-702.

Marti, H.J ., Bernaudin, M., Bellail, A., Schoch, H., Euler, M., Petit, E. \& Risau, W. (2000) Hypoxia-induced vascular endothelial growth factor expression precedes neovascularization after cerebral ischemia. AmJ Pathol, 156, 965-976.

Matsuzaki, H., Tamatani, M., Yamaguchi, A., Namikawa, K., Kiyama, H., Vitek, M.P., Mitsuda, N. \& Tohyama, M. (2001) Vascular endothelial growth factor rescues hippocampal neurons from glutamate-induced toxicity: signal transduction cascades. FASEB J , 15, 1218-1220.

Mautes, A.E., Weinzierl, M.R., Donovan, F. \& N oble, L.J . (2000) Vascular events after spinal cord injury: contribution to secondary pathogenesis. Phys Ther, 80, 673-687.

Meyer, R.D. \& Rahimi, N. (2003) Comparative structure-function analysis of VEGFR-1 and VEGFR-2: What have we learned from chimeric systems? Ann N Y Acad Sci, 995, 200-207.

Narayana, P.A., Grill, R.J ., Chacko, T. \& Vang, R. (2004) Endogenous recovery of injured spinal cord: Iongitudinal in vivo magnetic resonance imaging. J Neurosci Res, 78, 749-759.

Nori, S., Okada, Y., Yasuda, A., Tsuji, O., Takahashi, Y., Kobayashi, Y., Fujiyoshi, K., Koike, M., Uchiyama, Y., I keda, E., Toyama, Y., Yamanaka, S., Nakamura, M. \& Okano, H. (2011) Grafted human-induced pl uripotent stem-cell-derived neurospheres promote motor functional recovery after spinal cord injury in mice. Proc Natl Acad Sci U SA, 108, 16825-16830.

Ogunshola, O.O., Antic, A., Donoghue, M.J ., Fan, S.Y., Kim, H., Stewart, W.B., Madri, J .A. \& Ment, L.R. (2002) Paracrine and autocrine functions of neuronal vascular endothelial growth factor (VEGF) in the central nervous system. J Biol Chem, 277, 11410-11415.

Ohki, Y., Heissig, B., Sato, Y., Akiyama, H., Zhu, Z., Hicklin, D.J ., Shimada, K., Ogawa, H., Daida, H., Hattori, K. \& Ohsaka, A. (2005) Granulocyte colony-stimulating factor promotes neovascularization by releasing vascular endothelial growth factor from neutrophils. FASEB J , 19, 2005-2007.

Olsson, A.K., Dimberg, A., Kreuger, J . \& Claesson-Welsh, L. (2006) VE GF receptor signalling - in control of vascular function. Nat Rev Mol Cell Biol, 7, 359-371. 
Oosthuyse, B., Moons, L., Storkebaum, E., Beck, H., Nuyens, D., Brusselmans, K., Van Dorpe, J ., Hellings, P., Gorselink, M., Heymans, S., Theilmeier, G., Dewerchin, M., Laudenbach, V., Vermylen, P., Raat, H., Acker, T., Vleminckx, V., Van Den Bosch, L., Cashman, N., Fujisawa, H., Drost, M.R., Sciot, R., Bruyninckx, F., Hicklin, D.J ., Ince, C., Gressens, P., Lupu, F., Plate, K.H., Robberecht, W., Herbert, J .M., Collen, D. \& Carmeliet, P. (2001) Deletion of the hypoxia-response element in the vascular endothelial growth factor promoter causes motor neuron degeneration. Nat Genet, 28, 131-138.

Patel, C.B., Cohen, D.M., Ahobila-Vajjula, P., Sundberg, L.M., Chacko, T. \& Narayana, P.A. (2009) Effect of VEGF treatment on the blood-spinal cord barrier permeability in experimental spinal cord injury: dynamic contrast-enhanced magnetic resonance imaging. J Neurotrauma, 26, 1005-1016.

Paul, R., Zhang, Z.G., Eliceiri, B.P., J iang, Q., Boccia, A.D., Zhang, R.L., Chopp, M. \& Cheresh, D.A. (2001) Src deficiency or blockade of Src activity in mice provides cerebral protection following stroke. Nat Med, 7, 222-227.

Pitchford, S.C., Lodie, T. \& Rankin, S.M. (2012) VEGFR1 stimulates a CXCR4-dependent translocation of megakaryocytes to the vascular niche, enhancing platelet production in mice. Blood, 120, 2787-2795.

Popovich, P.G., Horner, P.J ., Mullin, B.B. \& Stokes, B.T. (1996) A quantitative spatial analysis of the blood-spinal cord barrier. I. Permeability changes after experimental spinal contusion injury. Exp Neurol, 142, 258-275.

Proescholdt, M.A., Heiss, J .D., Walbridge, S., Muhlhauser, J ., Capogrossi, M.C., Oldfield, E.H. \& Merrill, M.J . (1999) Vascular endothelial growth factor (VEGF) modulates vascular permeability and inflammation in rat brain. J Neuropathol Exp Neurol, 58, 613-627.

Rosenstein, J .M., Mani, N., Khaibullina, A. \& Krum, J .M. (2003) Neurotrophic effects of vascular endothelial growth factor on organotypic cortical explants and primary cortical neurons. J Neurosci, 23, 11036-11044.

Rosenstein, J .M., Mani, N., Silverman, W.F. \& Krum, J .M. (1998) Patterns of brain angiogenesis after vascular endothelial growth factor administration in vitro and in vivo. ProcNatI Acad Sci U SA, 95, 7086-7091. 
Sawano, A., I wai, S., Sakurai, Y., I to, M., Shitara, K., Nakahata, T. \& Shibuya, M. (2001) FIt-1, vascular endothelial growth factor receptor 1 , is a novel cell surface marker for the lineage of monocyte-macrophages in humans. Blood, 97, 785-791.

Schoch, H.J ., Fischer, S. \& Marti, H.H. (2002) Hypoxia-induced vascular endothelial growth factor expression causes vascular leakage in the brain. Brain, 125, 2549-2557.

Schreurs, M.P., Houston, E.M., May, V. \& Cipolla, M.J . (2012) The adaptation of the blood-brain barrier to vascular endothelial growth factor and placental growth factor during pregnancy. FASEB J , 26, 355-362.

Shimotake, J ., Derugin, N., Wendland, M., Vexler, Z.S. \& Ferriero, D.M. (2010) Vascular endothelial growth factor receptor- 2 inhibition promotes cell death and limits endothelial cell proliferation in a neonatal rodent model of stroke. Stroke, 41, 343-349.

Shingu, H., Kimura, I., Nasu, Y., Shiotani, A., Oh-hama, M., Hijioka, A. \& Tanaka, J . (1989) Microangiographic study of spinal cord injury and myelopathy. Paraplegia, 27, 182-189.

Shiote, M., Nagano, I., Ilieva, H., Murakami, T., Narai, H., Ohta, Y., Nagata, T., Shoji, M. \& Abe, K. (2005) Reduction of a vascular endothelial growth factor receptor, fetal liver kinase-1, by antisense oligonucleotides induces motor neuron death in rat spinal cord exposed to hypoxia. Neuroscience, 132, 175-182.

Silverman, W.F., Krum, J .M., Mani, N. \& Rosenstein, J .M. (1999) Vascular, glial and neuronal effects of vascular endothelial growth factor in mesencephalic explant cultures. Neuroscience, 90, 1529-1541.

Silvestre, J .S., Tamarat, R., Ebrahimian, T.G., Le-Roux, A., Clergue, M., Emmanuel, F., Duriez, M., Schwartz, B., Branellec, D. \& Levy, B.I. (2003) Vascular endothelial growth factor-B promotes in vivo angiogenesis. Circ Res, 93, 114-123.

Skold, M.K., Marti, H.H., Lindholm, T., Linda, H., Hammarberg, H., Risling, M. \& Cullheim, S. (2004) Induction of HIF 1alpha but not HIF 2alpha in motoneurons after ventral funiculus axotomy-implication in neuronal survival strategies. Exp Neurol, 188, 20-32.

Skold, M.K., von Gertten, C., Sandberg-Nordqvist, A.C., Mathiesen, T. \& Holmin, S. (2005) VEGF 
and VEGF receptor expression after experimental brain contusion in rat. / Neurotrauma, 22, 353-367.

Sondell, M., Lundborg, G. \& Kanje, M. (1999) Vascular endothelial growth factor has neurotrophic activity and stimulates axonal outgrowth, enhancing cell survival and Schwann cell proliferation in the peripheral nervous system. / Neurosci, 19, 5731-5740.

Sondell, M., Sundler, F. \& Kanje, M. (2000) Vascular endothelial growth factor is a neurotrophic factor which stimulates axonal outgrowth through the flk-1 receptor. Eur J Neurosci, 12, 4243-4254.

Sun, Y., J in, K., Xie, L., Childs, J ., Mao, X.O., Logvinova, A. \& Greenberg, D.A. (2003) VEGF-induced neuroprotection, neurogenesis, and angiogenesis after focal cerebral ischemia. J Clin Invest, 111, 1843-1851.

Sundberg, L.M., Herrera, J J . \& Narayana, P.A. (2010) In vivo longitudinal MRI and behavioral studies in experimental spinal cord injury. J Neurotrauma, 27, 1753-1767.

Takahashi, H. \& Shibuya, M. (2005) The vascular endothelial growth factor (VEGF)NEGF receptor system and its role under physiological and pathological conditions. Clin Sci (Lond), 109, 227-241.

Tator, C.H. \& Koyanagi, I. (1997) Vascular mechanisms in the pathophysiology of human spinal cord injury. J Neurosurg, 86, 483-492.

Tsuji, O., Miura, K., Okada, Y., Fujiyoshi, K., Mukaino, M., Nagoshi, N., Kitamura, K., Kumagai, G., Nishino, M., Tomisato, S., Higashi, H., Nagai, T., Katoh, H., Kohda, K., Matsuzaki, Y., Yuzaki, M., I keda, E., Toyama, Y., Nakamura, M., Yamanaka, S. \& Okano, H. (2010) Therapeutic potential of appropriately evaluated safe-induced pluripotent stem cells for spinal cord injury. Proc Nat/ Acad Sci U SA, 107, 12704-12709.

Usui, T., I shida, S., Yamashiro, K., Kaji, Y., Poulaki, V., Moore, J ., Moore, T., Amano, S., Horikawa, Y., Dartt, D., Golding, M., Shima, D.T. \& Adamis, A.P. (2004) VEGF 164(165) as the pathological isoform: differential leukocyte and endothelial responses through VEGFR1 and VEGFR2. Invest Ophthalmol Vis Sci, 45, 368-374.

van Bruggen, N., Thibodeaux, H., Palmer, J .T., Lee, W.P., Fu, L., Cairns, B., Tumas, D., Gerlai, R., 
Williams, S.P., van Lookeren Campagne, M. \& Ferrara, N. (1999) VEGF antagonism reduces edema formation and tissue damage after ischemia/reperfusion injury in the mouse brain. J Clin Invest, 104, 1613-1620.

Vogel, C., Bauer, A., Wiesnet, M., Preissner, K.T., Schaper, W., Marti, H.H. \& Fischer, S. (2007) FIt-1, but not FIk-1 mediates hyperpermeability through activation of the PI3-K/Akt pathway. J Cell Physiol, 212, 236-243.

Westergren, H., Farooque, M., Olsson, Y. \& Holtz, A. (2001) Spinal cord blood flow changes following systemic hypothermia and spinal cord compression injury: an experimental study in the rat using Laser-Doppler flowmetry. Spinal Cord, 39, 74-84.

Widenfalk, J ., Lipson, A., J ubran, M., Hofstetter, C., Ebendal, T., Cao, Y. \& Olson, L. (2003) Vascular endothelial growth factor improves functional outcome and decreases secondary degeneration in experimental spinal cord contusion injury. Neuroscience, 120, 951-960.

Winkler, F., Kozin, S.V., Tong, R.T., Chae, S.S., Booth, M.F., Garkavtsev, I., Xu, L., Hicklin, D.J ., Fukumura, D., di Tomaso, E., Munn, L.L. \& J ain, R.K. (2004) Kinetics of vascular normalization by VEGFR2 blockade governs brain tumor response to radiation: role of oxygenation, angiopoi etin-1, and matrix metalloproteinases. Cancer Cell, 6, 553-563.

Yang, W. \& de Bono, D.P. (1997) A new role for vascular endothelial growth factor and fibroblast growth factors: increasing endothelial resistance to oxidative stress. FEBS Lett, 403, 139-142.

Yasuda, A., Tsuji, O., Shibata, S., N ori, S., Takano, M., Kobayashi, Y., Takahashi, Y., F ujiyoshi, K., Hara, C.M., Miyawaki, A., Okano, H.J ., Toyama, Y., Nakamura, M. \& Okano, H. (2011) Significance of remyelination by neural stem/progenitor cells transplanted into the injured spinal cord. Stem Cel/s, 29, 1983-1994.

Zhang, Z.G., Zhang, L., J iang, Q., Zhang, R., Davies, K., Powers, C., Bruggen, N. \& Chopp, M. (2000) VEGF enhances angiogenesis and promotes blood-brain barrier leakage in the ischemic brain. J Clin Invest, 106, 829-838.

Zhang, Z.G., Zhang, L., Tsang, W., Soltanian-Zadeh, H., Morris, D., Zhang, R., Goussev, A., Powers, C., Yeich, T. \& Chopp, M. (2002) Correlation of VEGF and angiopoietin expression with disruption of blood-brain barrier and angiogenesis after focal cerebral ischemia. J Cereb 
Blood Flow Metab, 22, 379-392. 


\section{Figure Legend}

Figure 1. The effects of blockade of VEGF-R1 and VEGF-R2 on the number of apoptotic neural cells in the acute phase of spinal cord injury.

(A-C) Representative images of the lesion epicenter in spinal cords obtained $8 \mathrm{~h}$ after contusion and immunostained with anti-NeuN antibodies (A) or anti-cleaved caspase-3 antibodies (B). C is the merged image of A and B and shows both live neural cells and apoptotic neural cells. There was no obvious reduction in the number of neuronal cells, but some cells were positive for anti-cleaved caspase-3, indicating that they were apoptotic. (D) The number of neural cells measured in different regions of NeuN-stained axial sections of the dissected spinal cord. The number of neural cells was similar in VEGF-R1-neutralized (white bars), VEGF-R2-neutralized (gray bars), and control (black bars) mice. (E) The number of apoptotic neural cells (double-positive cells) measured in different regions of double-stained axial sections of the dissected spinal cord. The number of apoptotic neural cells was higher in VEGF-R2-neutralized mice (gray bars) than in VEGF-R1-neutralized (white bars) and control group (black bars) mice. ** indicates $\mathrm{P}<0.01$. Scale bar, $50 \mu \mathrm{m}$. VEGF-R1, vascular endothelial growth factor receptor 1. VEGF-R2, vascular endothelial growth factor receptor 2 . 


\section{Figure 2. The effects of blockade of VEGF-R1 and VEGF-R2 on permeability and}

infiltration of inflammatory cells in the acute phase of spinal cord injury.

(A-C) Representative images of dextran tetramethylrhodamine (dextran-TMR) in the lesion epicenter in spinal cords obtained from VEGF-R1-neutralized mice (A),

VEGF-R2-neutralized mice (B), and control mice (C) in the acute phase of spinal cord injury (dextran-TMR injected $8 \mathrm{~h}$ after contusion, and spinal cords dissected $9 \mathrm{~h}$ after contusion). (D-F) Representative images of CD11b-positive inflammatory cells in the lesion epicenter of each group in comparable order. $(G)$ The permeability in the acute phase was significantly reduced in the VEGF-R1-neutralized group (white bars) compared with the control group (black bars). (H) Infiltration of inflammatory cells was significantly reduced in the VEGF-R1-neutralized group (white bars) compared with the VEGF-R2-neutralized group (gray bars) and the control group (black bars). * indicates $\mathrm{P}<0.05$. Scale bar, $100 \mu \mathrm{m}$. VEGF, vascular endothelial growth factor. VEGF-R1, vascular endothelial growth factor receptor 1. VEGF-R2, vascular endothelial growth factor receptor 2. dextran-TMR, dextran tetramethylrhodamine. 


\section{Figure 3. The effects of blockade of VEGF-R1 and VEGFR-2 on neural tissue in the}

\section{chronic phase of spinal cord injury.}

(A-C) Representative images of HE-stained sections of the spinal cord obtained from

VEGF-R1-neutralized mice (A), VEGF-R2-neutralized mice (B), and control mice (C) $56 \mathrm{~d}$ after contusion. (D) Epicenter lesion showing a remarkable reduction of residual tissue. The VEGF-R2-neutralized group (gray bars) showed a significant loss of tissue area compared with the VEGF-R1-neutralized group (white bars) and control group (black bars). (E-G) Representative images of Nissl-stained sections of the spinal cord obtained from VEGF-R1-neutralized mice (E), VEGF-R2-neutralized mice (F), and control mice (G) 56 d after contusion. All groups showed few intact neural cells at the lesion epicenter. $(\mathrm{H})$ Nissl-stained neural cells are markedly decreased in the epicenter in all groups. VEGF-R2-neutralized group (gray bars) also showed a significant reduction of neural cells in rostal and caudal lesions compared with the control group (black bars). (I-K) Representative images of EC-stained sections of the spinal cord obtained from VEGF-R1-neutralized mice (I), VEGF-R2-neutralized mice (J), and control mice (K) $56 \mathrm{~d}$ after contusion. (L) VEGF-R2-neutralized group (gray bars) showed significant aggravation of myelinated fibers compared with the VEGF-R1-neutralized group (white bars) and control group (black bars). * indicates $\mathrm{P}<0.05$, and $* *$ indicates $\mathrm{P}<0.01$. Scale bar, $200 \mu \mathrm{m}$. VEGF, vascular endothelial 
growth factor. VEGF-R1, vascular endothelial growth factor receptor 1. VEGF-R2, vascular endothelial growth factor receptor 2 .

Figure 4. The effects of blockade of VEGF-R1 and VEGFR-2 on endothelial cells and serotonergic fibers in the chronic phase of spinal cord injury.

(A) Representative image of PECAM-1-positive endothelial cells in the sagittal section of spinal cord obtained $56 \mathrm{~d}$ after contusion. A couple of capillary vessels are evident in each section, and vessel walls are sparsely lined with endothelial cells. (B) 5-HT-positive serotonergic fibers were seen in both white matter and gray matter. (C) Some serotonergic fibers are touching endothelial cells. (D) Endothelial cell number is reduced in the epicenter and caudal lesion (VEGF-R1-neutralized mice, white bar; VEGF-R2-neutralized mice, gray bar; control mice, black bar). (E) The amount of serotonergic fibers increased in the rostal lesion near the epicenter (VEGF-R1-neutralized mice, white bar; VEGF-R2-neutralized mice, gray bar; control mice, black bar). (F) The relation between the number of endothelial cells and the amount of serotonergic fibers calculated from all lesions of all groups $(n=81)$. The correlation coefficient was moderate $(\mathrm{r}=0.47)$ but significant. $* * *$ indicates $\mathrm{P}<0.001$. Scale bar, $50 \mu \mathrm{m}$. VEGF, vascular endothelial growth factor. VEGF-R1, vascular endothelial growth factor receptor 1. VEGF-R2, vascular endothelial growth factor receptor 2. 
Figure 5. The effects of blockade of VEGF-R1 and VEGFR-2 on locomotor function and electrophysiology after spinal cord injury

(A) Hindlimb motor function each week after contusion assessed using the Basso mouse scale (BMS) score in VEGF-R1-neutralized, VEGF-R2-neutralized, and control mice. (B) Motor evoked potential latency measured $56 \mathrm{~d}$ weeks after contusion in VEGF-R1-neutralized mice, VEGF-R2-neutralized mice, and control mice. * indicates $\mathrm{P}<0.05$. VEGF, vascular endothelial growth factor. VEGF-R1, vascular endothelial growth factor receptor 1. VEGF-R2, vascular endothelial growth factor receptor 2 .

Figure 6. Roles of endogenous vascular endothelial factor receptor 1 and 2 after spinal cord injury Vascular endothelial growth factor receptor 1 (VEGF-R1) is expressed in endothelial cells and monocytes. Downstream pathway of VEGF-R1 in endothelial cells leads to hyperpermeability of blood-brain-barrier. Monocytes are stimulated to migrate into spinal cord tissue via VEGF-R1. Vascular endothelial growth factor receptor 2 (VEGF-R2) is expressed in endothelial cells and neural cells. Survival of endothelial cells and preservation of microcirculation might be promoted by VEGF-R2 (dashed arrow). VEGF-R2 contributes to 
the protection of neuronal cell from spinal cord injury via PI3-K/Akt pathway. Final biological outcomes that are coupled to the respective receptors are indicated in blue boxes. VEGF-R1, vascular endothelial growth factor receptor 1. VEGF-R2, vascular endothelial growth factor receptor 2. PI3-K, phosphatidylinositide 3-kinase. 
Figure 1
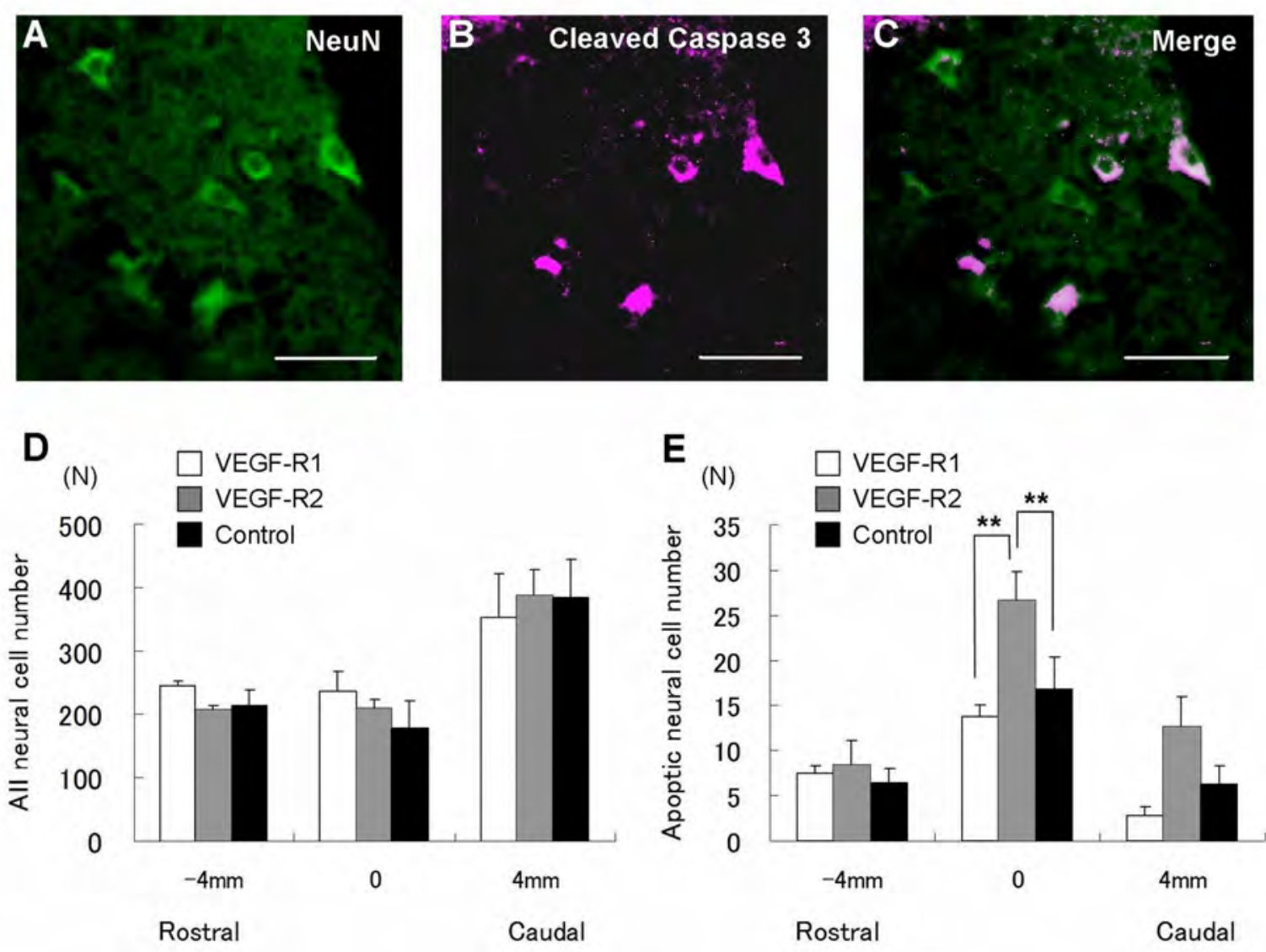
Figure 2
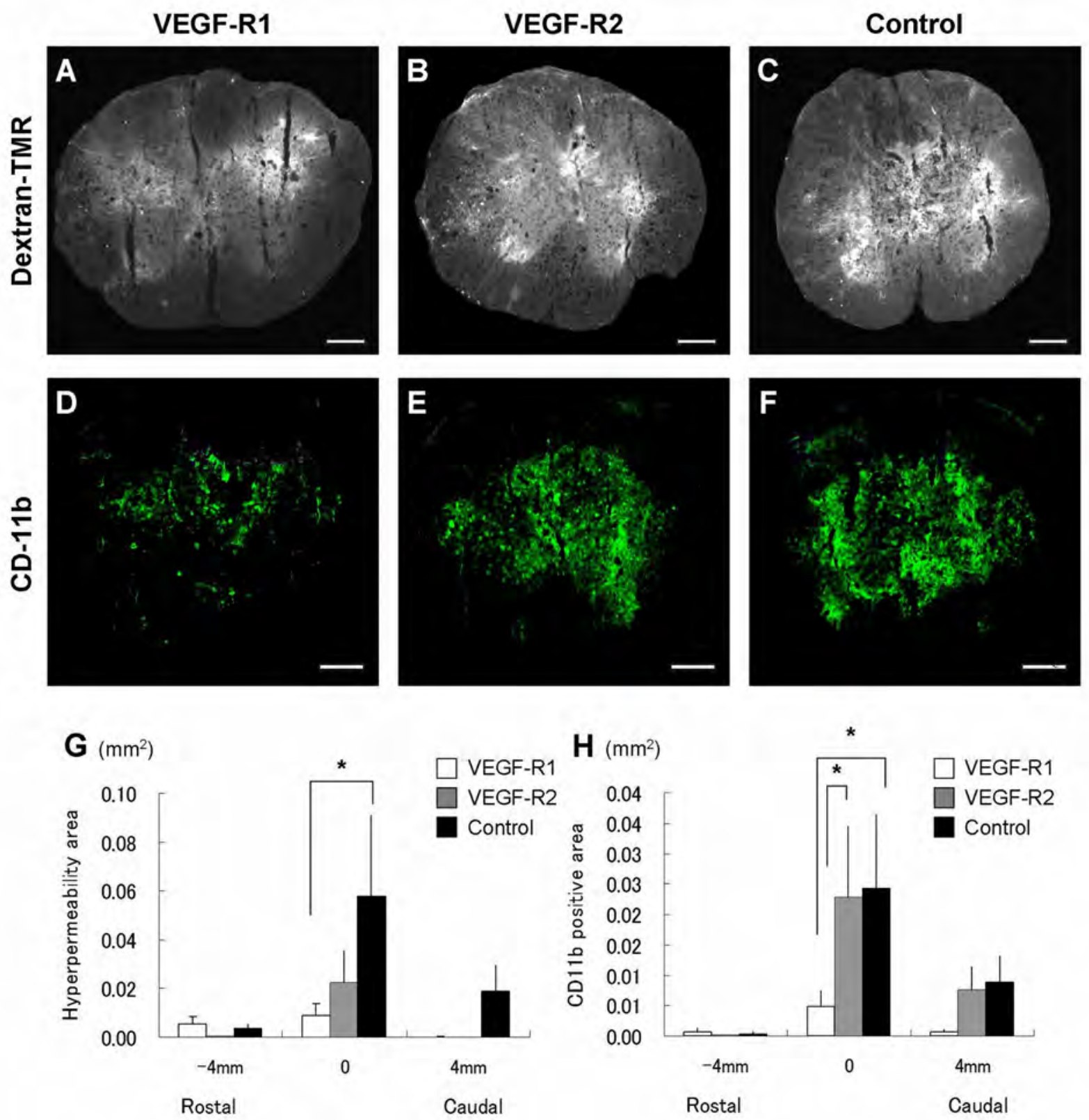


\section{Figure 3}

Hematoxylin Eosin
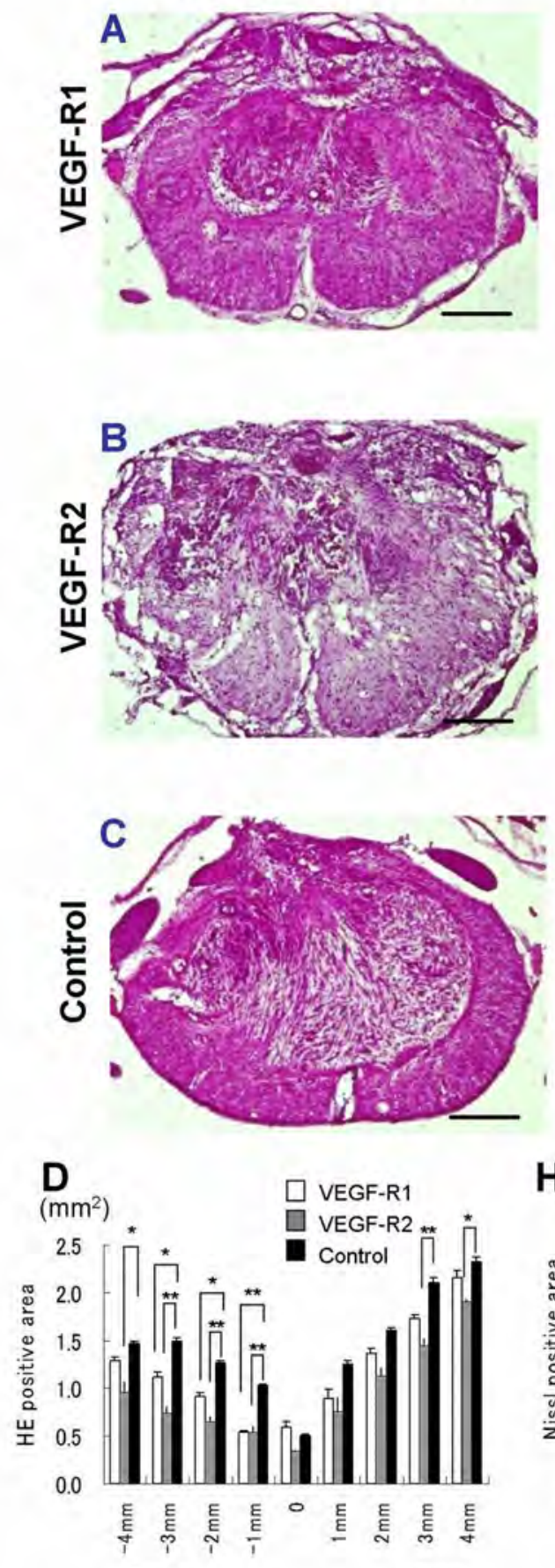

Rostral

Caudal

\section{NissI}
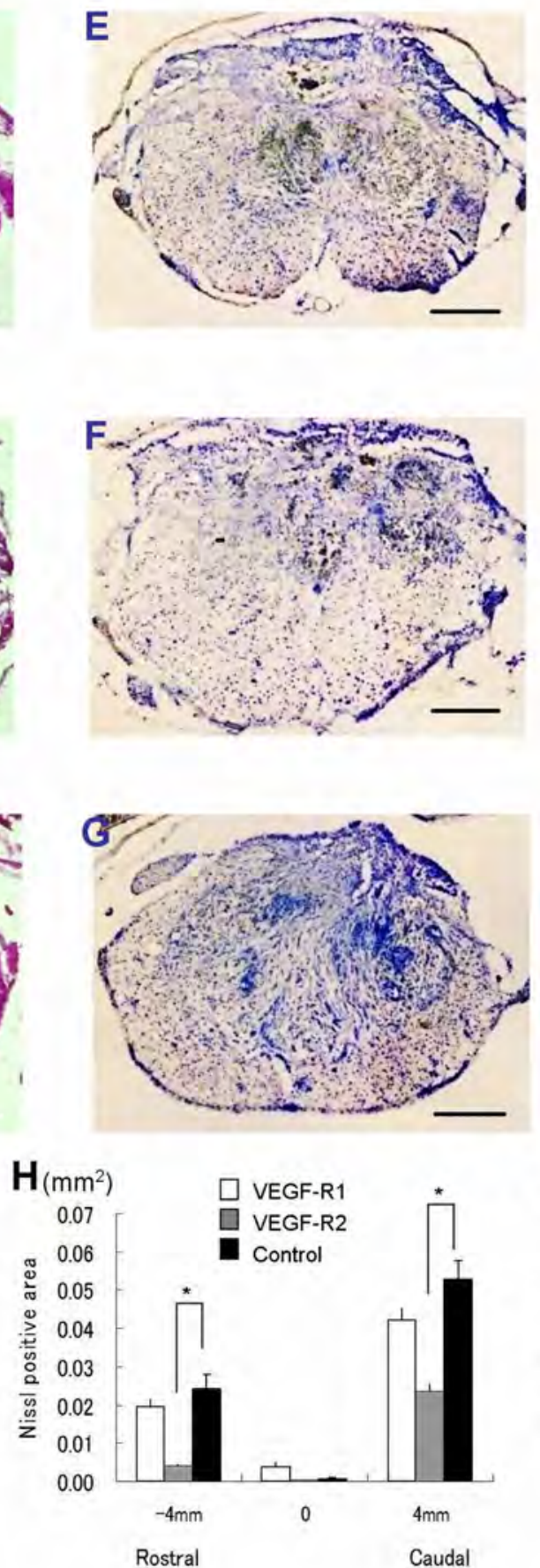

\section{Eriochrome Cyanine}
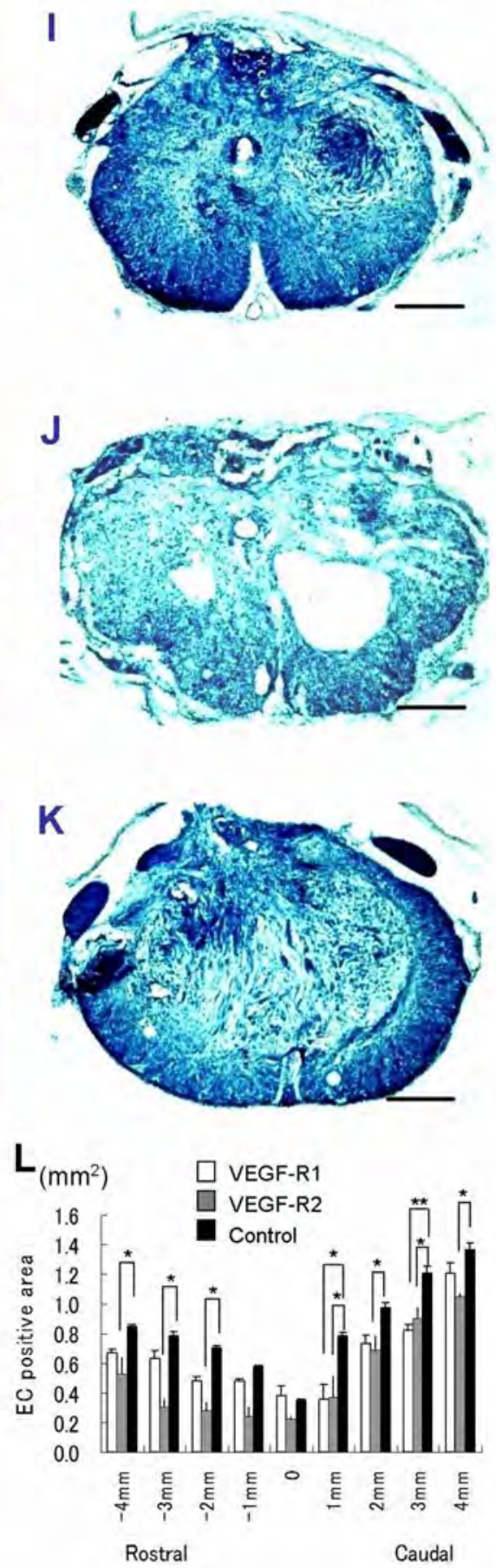
Figure 4

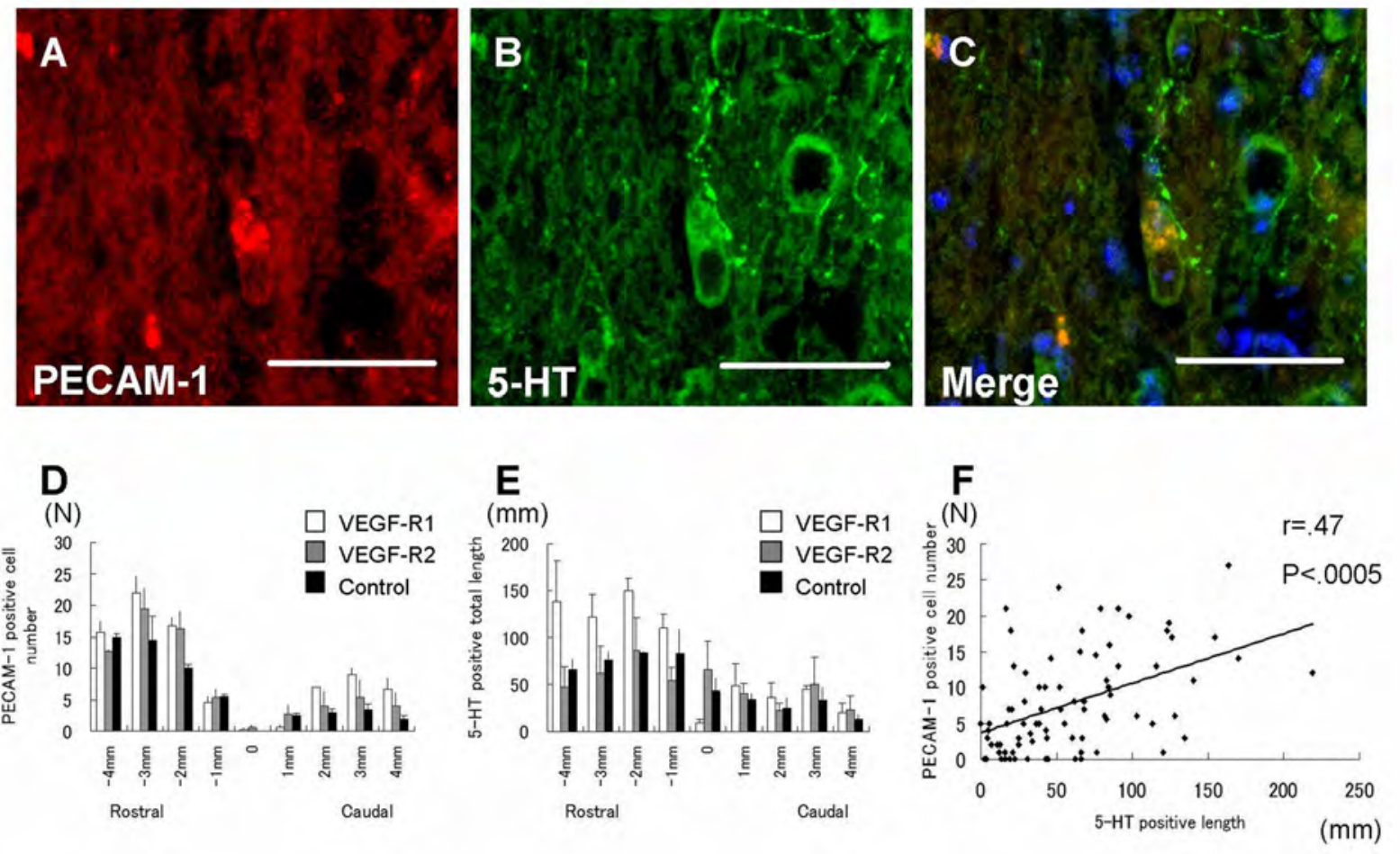


Figure 5
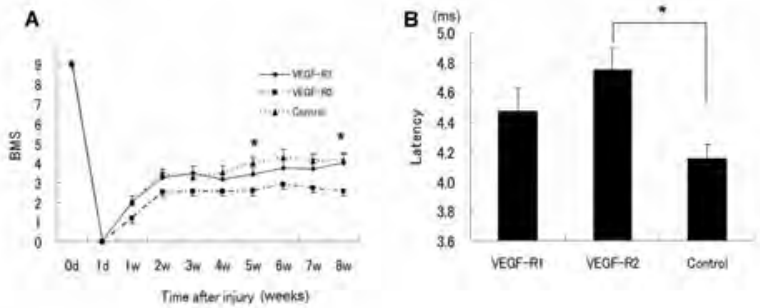

Time after injury (weeks) 


\section{Figure 6}

\section{Blood vessel}

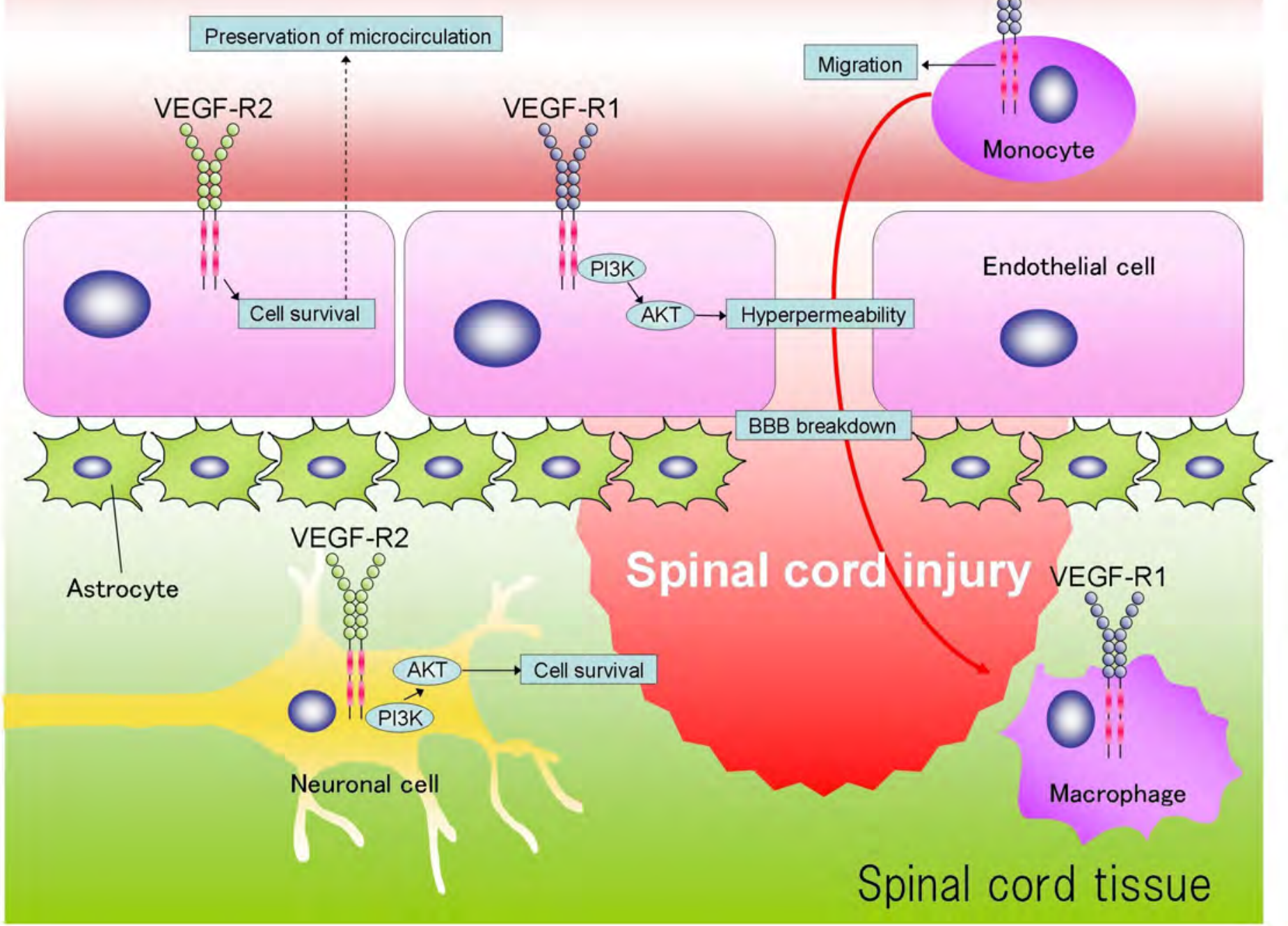

